\title{
A TEMÁTICA DE ÁLCOOL \\ E OUTRAS DROGAS NA \\ EXTENSÃO E PARA A \\ FORMAÇÃO ACADÊMICA
}

\section{THE SUBJECT OF ALCOHOL AND OTHER DRUGS IN OUTREACH ACTIVITIES AND ACADEMIC EDUCATION}

Maria de Nazareth Rodrigues Malcher de Oliveira Silva* Camila Isabel Cruz Souza* Andrea Donatti Gallassi***

\section{RESUMO}

A atividade de extensão integra ensino, extensão e pesquisa. Este estudo descreve as atividades de extensão sobre álcool e outras drogas desenvolvidas pelas instituições públicas de ensino superior, refletindo sobre a importância de incluir temáticas atuais e transversais nas áreas da saúde, como as drogas e vulnerabilidades associadas. É parte integrante do Programa de Extensão Centro de Referências sobre Drogas e Vulnerabilidades Associadas, por meio do Projeto de Extensão Roda de Debate sobre Drogas e Vulnerabilidades Associadas, o qual estimula o debate sobre a problemáticas das drogas e as vulnerabilidades associadas com profissionais de saúde. Utilizou como método o estudo descritivo de projetos de extensão. Os dados apresentaram que há muitos investimentos de formação para profissionais da rede intersetorial, como resposta ao investimento público, e uma limitação no ensino superior, no cotidiano acadêmico. É relevante a utilização das atividades de extensão sobre a temática das drogas, junto aos discentes, para uma formação reflexiva e crítica.

Palavras-chave: Extensão universitária; álcool e outras drogas; formação acadêmica.

\section{ABSTRACT}

The outreach activity involves teaching, outreach and research. This study aims to reports the outreach activities conducted by public institutions of higher education on the subject of alcohol and other drugs. It also reflects on the importance of including current and cross-cutting issues in the areas of health, such as drugs and associated vulnerabilities. It is part of the outreach program Center of Excellence in Drugs and Associated Vulnerabilities (Centro de Referências sobre Drogas e Vulnerabilidades Associadas) through the outreach project Group of Discussion (Roda de Debates) which aims to encourage debate on issues related to drugs and vulnerabilities associated with health professionals. As method, it was used the descriptive

\footnotetext{
* Professora da Universidade de Brasília (UnB), DF - Brasil. E-mail: malchersilva@unb.br

** Aluna de graduação da Universidade de Brasília (UnB), DF - Brasil. E-mail: camilaisa.95@gmail.com

*** Professora da Universidade de Brasília (UnB), DF - Brasil. E-mail: andrea.gallassi@gmail.com
} 
study of outreach projects. The data show that the training of professionals of intersectoral network is larger due public investments and that there are limitations to the higher education system on daily basis. It should be noted the relevance of developing outreach activities on the subject of drugs with students from universities in order to promote reflexive and critical learning.

Keywords: Outreach; Alcohol and other drugs; Academic education.

\section{Introduçáo}

De acordo com Lobato, Abranches e Rodrigues (2012), a atividade de extensão nas Instituições de Ensino Superior (IES) é considerada como um resultado do processo social iniciado na década de 1930 e que, até a década de 1960, gerava aos discentes apenas um espaço de aprendizagem, como uma forma de atualização. Com a criação da Lei da Reforma Universitária, em 1968, foi incluída a indissociabilidade entre ensino e pesquisa nas IES, o que gerou o desenvolvimento de assistência à população, mas também o estímulo ao processo formativo acadêmico.

Entretanto, foi somente na década de 1980, por meio do I Fórum de Pró-Reitores das Universidades Públicas - FORPROEX, que foi criada a Política Nacional de Extensão Universitária, a qual incluiu a extensão como um espaço de reflexáo crítica, que deveria colaborar para clarear o conhecimento e o agir da Universidade, em consonância à Lei de Diretrizes e Bases da Educação Nacional (LDB). Assim, a LBD institui que as universidades forneçam ensino, pesquisa e extensão, por meio dos princípios da indissociabilidade, tornando obrigatória a sua inclusão nos projetos políticos-pedagógicos dos cursos, tendo como desafio a inserção dessa lógica nas grades curriculares.

Processualmente, a atividade de extensão neste formato vem ganhando notoriedade, como uma atividade presente no cotidiano dos universitários e que busca, cada vez mais, uma relação ensino serviço e um processo reflexivo. (RIBEIRO, 2009).

Segundo o Projeto Político-Pedagógico Institucional - PPPI da Universidade de Brasília - UnB (BRASÍLIA, 2011, p. 36), a extensão universitária "deve desenvolver troca de saberes, relação dialógica que possibilite o empoderamento mútuo da sociedade e da universidade", permitindo que os acadêmicos busquem construir a formação de acordo com suas afinidades e interesses.

A associação entre ensino, pesquisa e extensão, bem vinculada nas atividades acadêmicas, acarreta mudanças relevantes nos processos de ensino e aprendizagem, contribuindo de forma ativa para a formação profissional de discentes e docentes, fortalecendo as habilidades e competências para o ensinamento de contextos relacionados às práticas profissionais (RODRIGUES, 2011). Neste sentido, possibilita a produção de espaço de interação ensino serviço, mas também desenvolve conhecimento sobre temáticas atuais, como a problemática do consumo de álcool e outras drogas e as vulnerabilidades associadas a esse consumo.

Para Assis e Bonifácio (2011), durante a formação acadêmica, o discente deve assimilar o conhecimento não somente na sala de aula, mas também por meio de sua participação em projetos de extensão, onde terá contato com a comunidade e com a pesquisa científica, promovendo uma formação ampla.

$\mathrm{Na}$ formação superior em saúde, mudanças históricas e significativas, ao longo dos tempos, ocorreram para responder ao paradigma do cuidado e nas políticas públicas inovadoras, como o Sistema Único de Saúde (SUS), a Política de Saúde Mental e a Política Nacional sobre Drogas. Esse processo modificou a forma do entendimento sobre o ser humano e sobre a relação saúde-doença, acarretando mudanças na formação dos profissionais de saúde. 
A Reforma Psiquiátrica (Lei 10.216 GM/MS de 2002) foi uma das transformações ocorridas no campo da saúde mental, álcool e outras drogas, o que incitou mudanças nas habilidades e competências nos cursos de saúde (BRASIL, 2002).

Outro fato importante foi o Programa Crack é Possível Vencer, implantado em 2011 pelo Ministério da Justiça, em parceria com outros Ministérios, com recursos focados em três eixos de atuação: cuidado, autoridade e prevenção. Os objetivos eram: estruturar a rede de atençáo no cuidado do uso problemático de álcool e outras drogas e seus familiares; reprimir o tráfico, o crime organizado e garantir a segurança pública; fortalecer o vínculo familiar e comunitário; reduzir os fatores de risco associados ao uso de drogas; e capacitar a rede de atenção para oferecer um melhor cuidado junto àqueles que dele necessitam (BRASIL, 2013).

Este Plano incentivou os diversos serviços intersetoriais, mas também colocou as IES como protagonistas na formaçáo continuada e permanente dos profissionais, por meio dos Centros Regionais de Referências (CRR), em parceria com as instituições públicas de ensino superior. Assim, passou a desenvolver açôes presenciais de educação permanente sobre a temática das drogas para os profissisonais que compóem a rede integrada de atenção, composta pelas instituiçôes de saúde, de assistência social, de educaçáo, segurança pública, Ministério Público, Poder Judiciário, instituiçóes que compõem o Sistema Nacional de Socioeducação (SINASE) - que atendem adolescentes em cumprimento de medida socioeducativa - como também para mapear e articular os diferentes setores que atuam na abordagem desta população. (BRASIL, 2012).

Nos CRRs, o processo formativo possibilitou que as IES ampliassem suas açóes de extensão e pesquisa, favorecendo a indissociabilidade ensino, extensão e pesquisa instituído pela política de educação superior e pelas diretrizes curriculares para os cursos de saúde.

É importante destacar que, no Plano de Reestruturação Universitária (REUNI), as Diretrizes Curriculares dos Cursos de Graduação (DCNS) são consideradas estratégias para mudanças dos projetos político-pedagógicos dos cursos e, dessa forma, para delinear um perfil de habilidades e competências profissionais que respondam às necessidades instituídas nos parâmetros das políticas públicas, como a de drogas.

Barros, Santos, Mazoni, Dantas e Ferigolo (2008) ressaltam que a expansão, a diversidade e a complexidade problemática com o consumo abusivo de álcool e outras drogas e os modelos de cuidados inovadores incitam a necessidade de se estudar essa temática no cotidiano acadêmico, na forma que contemple o paradigma do modelo psicossocial, que vislumbre o sujeito, a substância usada e o contexto do consumo.

Nesse cenário, este estudo teve como objetivo descrever as atividades de extensão sobre álcool e outras drogas desenvolvidas pelas IES, refletindo sobre os investimentos nesta temática, entendendo a relevância da inclusão no cotidiano acadêmico como um campo contemporâneo de uma problemática de saúde pública e de políticas públicas inovadoras.

\section{Método}

Este estudo é do tipo descritivo, com dados quantitativo e qualitativo, para maior compreensão do fenômeno da pesquisa, a qual trata de apresentar o perfil das instituiçóes 
de ensino superior públicas em relação ao desenvolvimento de atividades de extensão relacionadas à temática das drogas.

A questão de pesquisa inicial do estudo ocorreu com base nas atividades desenvolvidas pelo Projeto de Extensáo: Roda de Debate sobre Drogas e Vulnerabilidades Associadas, que pertence ao Programa de Extensão Centro de Referência sobre Drogas e Vulnerabilidades Associadas, da Faculdade Ceilândia, Universidade de Brasília (CRR/ FCE/UnB).

O CRR/FCE/UnB é resultado dos investimentos dos editais do Plano Crack é Possível Vencer. Foi instituído em 2012 e desenvolve cursos de formação sobre a problemática das drogas nos serviços do Sistema Único de Saúde (SUS), Assistência Social (SUAS), educação, justiça, segurança pública e organizaçóes não governamentais. Os conteúdos oferecidos nos cursos correspondem ao projeto organizado e aprovado pela Secretaria Nacional sobre Drogas do Ministério da Justiça (SENAD/MJ), que avalia, aprova e acompanha as atividades formativas.

Para além do espaço formativo junto à rede intersetorial, o CRR/FCE/UnB ampliou suas atividades, promovendo continuidade desse espaço no ambiente acadêmico do ensino superior, como ocorre com o Projeto de Extensão Roda de Debate sobre Drogas e Vulnerabilidades Associadas. Este projeto de extensáo promove a continuidade das atividades formativas, porém junto aos discentes, em que os profissionais da rede intersetorial, participantes do CRR/FCE/UnB, atuam como mediadores da roda em debates sobre temáticas relacionadas às drogas.

A roda de debate acontece quinzenalmente, é aberta a toda comunidade acadêmica, e conta com dois mediadores (profissionais da rede intersetorial), que gerenciam o debate sobre a problemática das drogas, a partir de sua prática e do cotidiano do serviço. A cada semestre, os temas são levantados por meio dos Centros Acadêmicos dos Cursos da FCE/ UnB e do levantamento de sugestóes de temas realizado pelos participantes do semestre anterior. $\mathrm{O}$ cronograma das rodas é divulgado e toda a organização e logística das rodas sáo acompanhadas pelo CRR/FCE, por meio da coordenadora do Projeto e de alunos bolsistas de extensão.

A roda funciona desde 2013 e até o primeiro semestre de 2016 realizou 42 encontros, envolvendo 49 mediadores e uma média, a cada evento, de 60 discentes. Os debates desenvolvidos sáo voltados aos aspectos relevantes da atualidade. Entre alguns temas desenvolvidos, citam-se o tratamento compulsório e voluntário, a clínica da drogadição, o contexto do modelo de cuidado psicossocial, a descriminalização das drogas, a maioridade penal e vulnerabilidades da juventude, entre outros.

Os mediadores, a cada roda, desenvolvem o debate, apresentando o serviço, o trabalho que realizam, assim como uma breve contextualização sobre o tema para fomentar a discussão. Os participantes debatem a partir das questóes apresentadas pelo mediador, reflexóes e críticas sobre o tema.

Ao final de cada roda, dez participantes são selecionados e convidados a responderem um questionário simplificado, com questóes referentes à roda de debate, ao aspecto de participação do debate, à percepção dos discente sobre questóes relacionadas à temática das drogas e à descrição de críticas e sugestôes de novos temas.

Portanto, a atividade de extensão da Roda de Debate instigou a necessidade de levantar nas IES outras atividades de extensão que tratem desta temática. Para isso, utilizou-se como estratégia a pesquisa em sites institucionais de universidades públicas 
federais, cujo critério de inclusão foram os sites de IES com cursos em saúde, em que se descreviam conteúdos sobre extensão.

Inicialmente, as IES foram levantadas no portal do Observatório Nacional de Informaçôes sobre Drogas - OBID (disponível em: www.obid.senad.org), site organizado pela Secretaria Nacional sobre Drogas do Ministério da Justiça (SENAD/MJ), que organiza e divulga a produçáo sobre a temática das drogas. Entre diversos conteúdos encontrados na página, consta a lista das IES públicas que estáo inscritas como instituiçôes de ensino que possuem CRR. Estas instituições foram também pesquisadas na Plataforma Carlos Chagas (disponível em: http://carloschagas.cnpq.br/), levantando-se os projetos de pesquisas na temática das drogas.

Posteriormente, foram localizados os sites das instituições de ensino, e os conteúdos sobre extensão na temática de álcool e outras drogas encontrados nos endereços virtuais foram estudados e os dados levantados, buscando-se nos documentos as variáveis, como: tipos de IES, local, população que atendem na extensão, ano de desenvolvimento, abordagem desenvolvida na extensão, tipo de atividades e associação de extensão com pesquisa. A planilha categorial de conteúdo oportunizou verificar a frequência das respostas das variáveis, que foram apresentadas descritivamente de forma numérica e de conteúdo.

O levantamento dos dados apresentou algumas limitaçóes, como ausência de material informativo sobre extensão nos sites, ou mesmo informaçôes incompletas e desatualizadas. Por este motivo, inicialmente, algumas IES foram descartadas do estudo. Os dados finais referem-se ao estudo em sites de 42 IES, entre Instituiçóes (25\%), Universidades (33\%) e Centros (42\%).

\section{Resultados}

O resultado do estudo das 42 IES nos sites selecionados abrangeu diversas regióes do país, como: 38\% da Regiâo Nordeste, 31\% Sudeste, 12\% da Regiấo Sul, 12\% da Região Centro Oeste e 7\% da Região Norte.

As IES descreveram os investimentos relacionados à temática das drogas, dentre os quais 12 sobre projetos de extensão, 42 associadas a projetos de pesquisa e 36 apenas sobre eventos acadêmicos. Houve um predomínio dessas atividades entre os anos de 2014 e 2015 (63\%).

Nos 12 projetos de extensão descritos nos sites, os objetivos foram relacionados como espaço para dialogar, promover estudos, pesquisas e açóes educativas em torno da temática álcool e outras drogas e suas consequências; melhorar as interaçôes interpessoais nas comunidades universitárias; articular o cuidado entre as redes de serviço do SUS e SUAS, bem como fortalecer a atuação dos profissionais na área de álcool, crack e outras drogas.

As atividades foram voltadas para grupos específicos, como: (1) profissionais de serviços de saúde mental (34\%); (2) pessoas em consumo problemático de drogas (14\%); (3) profissionais de serviços e comunidades (12\%); (4) apenas comunidades (12\%); e (5) com discentes (5\%). Além disso, $24 \%$ dos projetos de extensão não apresentaram a descrição sobre a população atendida. 
Os beneficiados pelos projetos de extensão foram os Centros de Atençáo Psicossocial - CAPS transtorno e álcool e drogas, os hospitais gerais, os ambulatórios de saúde mental, as residências terapêuticas e os consultórios na rua. Portanto, de modo geral, os projetos de extensão mostram-se com predomínio no serviço profissional e comunidade, ou mesmo com abordagem clínica, em detrimento à focada aos discentes nas IES, podendo estar relacionada à necessidade de responder as demandas produzidas pelos incentivos públicos, do Plano Crack é Possível Vencer, voltados para rede intersetorial e para formaçáo de profissionais em temas relacionados ao uso de drogas.

Esse foco junto aos profissionais nos serviços é visto na literatura como uma estratégia para oferecer diferentes ferramentas e alternativas para otimizar o processo ensino-aprendizagem (BARROS, et al., 2008; CHANDLER; FLETCHER;, VOLKOW, 2009; GALLASSI; DOS SANTOS, 2013). Porém, observa-se pouco espaço formativo das IES na educação superior, base para construção de competências para a atuação profissional.

As atividades de extensão realizadas nesses serviços mostraram-se diversificadas em dois focos: as abordagens clínicas (25\%), como as oficinas, atendimento de grupos, intervençôes clínicas e atividades de acolhimentos; e as preventistas e de promoçáo de saúde (33\%), como as palestras, os cursos e rodas de debate. Já $42 \%$ não especificaram as atividades que realizam.

Em 31 IES do estudo, além dos projetos de extensão, desenvolvem-se também eventos acadêmicos científicos, como as palestras e debates (75\%), congressos, simpósios, seminários e cursos (11\%). Portanto, são incentivadas aprendizagens nas temáticas das drogas no universo acadêmico. O objetivo dos eventos foi justificado com conteúdos relacionados à capacitação dos profissionais para intervir no problema, fortalecendo as práticas de intervenção e estimulando a elaboração de propostas de açôes para o combate ao uso do crack.

Entre os temas desenvolvidos nestes eventos, foram levantados: os fatores que levam ao envolvimento com drogas e seus malefícios; a discussáo sobre o cuidado e a qualidade de vida; orientações sobre os riscos, os esclarecimentos sobre a redução de danos, prevenção no campo das drogas; a atuação dos CAPS AD; as políticas públicas relacionadas ao campo; a Política Nacional sobre Drogas; as açôes de rede de cuidado e proteção social; metodologias clínicas e de reintegração social; e a legalização e descriminalização da maconha.

Assim, no geral, o foco está relacionado à capacitação, qualificação, educação continuada, divulgação de informaçóes acerca da temática, ao envolvimento junto aos jovens do ensino médio e fundamental, participação maior dos serviços da saúde pública e seus profissionais, construção de redes para melhor atender essa população, e conhecimento do perfil dos usuários e das complicações decorrentes do uso de álcool e drogas para o indivíduo e para a comunidade.

Observou-se uma predominância de atividades de extensão e pesquisa sobre a temática das drogas voltadas prioritariamente para o público externo às instituições de ensino superior, com diminuiçáo do tempo de espaços de aprendizagens sobre esta temática no cotidiano acadêmico.

Esses dados corroboram com estudos sobre as IES e a formaçáo de profissionais de saúde sobre a temática de drogas, que apresentam dados relevantes com relação 
aos graduandos de áreas relacionadas à saúde e a limitação de horários no currículo acadêmico para a aprendizagem sobre drogas de abuso. Por outro lado, pode-se constatar que, mesmo sendo uma temática transversal às diversas áreas da saúde, o seu acesso apresenta-se limitado, o que indica que a sua inclusăo nas universidades, nos espaços de extensão e pesquisa é favorável para competências interdisciplinares e que promovem outros formatos de aprendizagem, como a educação permanente, por meio da relação ensino serviço (MILLER; SHEPPARD, 1999; DACKIS; O'BRIEN, 2001; GALLASSI; DOS SANTOS, 2013).

Além disso, como medidas necessárias e urgentes, os planos para a educação superior, a partir de 2001, levaram as universidades a investirem nas necessidades e desafios do Século XXI, com avanços científicos e culturais, com pesquisa para a busca de soluçôes para problemas da atualidade e diminuição das desigualdades. Isso ocorreu por meio de estratégias para renovação do ensino universitário brasileiro, da reformulação do rígido sistema atual dos controles burocráticos, autonomia e permanente avaliação dos currículos (BRASIL, 2001; BRASIL, 2007; BRASÍLIA, 2013).

A elaboração do PNE se deu em um importante momento histórico-político, em 2001, e possibilitou ao Brasil investir em uma mudança no contexto universitário, com a integração curricular, a diversidade de cenários de aprendizagem, articulada ao Sistema Único de Saúde (SUS), por meio da concepçáo ampliada de saúde (BATISTA, 2005; BRASÍLIA, 2013) e da garantia do acesso às instituiçōes de ensino e de oportunidades de educação profissional (BRASIL, 2001).

A partir desse panorama, caracterizado pelo aumento da disponibilidade de drogas, reduçáo da idade de uso, alto impacto individual e social, e a abordagem restrita sobre o tema nos cursos de graduação, reconhece-se a necessidade de capacitar a rede de profissionais nos diversos setores envolvidos na atençáo aos usuários e familiares.

Ressalta-se a importância de favorecer investimento nos currículos acadêmicos do ensino superior, no sentido de ampliar espaços para atividades de ensino, extensão e pesquisa que envolvam a comunidade acadêmica em uma temática de saúde pública. Como exemplo a este contexto, encontra-se a experiência do Projeto de Extensão Roda de Debate sobre Crack, Outras Drogas e Vulnerabilidades Associadas, que contribui na criação, no aperfeiçoamento e na construção de uma relaçáo de comunicação constante e vinculada entre a Universidade e a Sociedade.

\section{Conclusóes}

O REUNI mostra-se como um plano inovador não apenas para expandir, mas melhorar a formação superior, aumentando recursos e reorientando a formação, que possibilite alcançar os novos paradigmas (como o de saúde e de saúde mental, relacionado ao uso problemático de álcool e outras drogas), com profissionais com competências política, técnica, ética e pedagógica para aplicabilidade nas situaçóes reais dos serviços no cotidiano do trabalho, mas que, principalmente, respondam às mudanças do modelo de saúde.

Esse cenário de mudanças na educação superior é significativo, mas com resultados ainda pouco expressivos no desenvolvimento do modelo de cuidado instituído pela 
Política de Saúde Mental, pois a formação em saúde ainda não incorporou os novos valores e princípios, comprometendo o desenvolvimento de competências para práticas que respondam ao modelo psicossocial. Isso gera, entre outros fatores, a necessidade de maiores investimentos de educação permanente em serviço como uma estratégia para superar essa lacuna.

Além disso, o estudo apresentou uma realidade atual, o investimento público nas IES para a formação de profissionais da rede intersetorial, que tem apresentado um fenômeno de desenvolvimento de competências e habilidades junto aos profissionais do serviço para lidar com a problemática das drogas. Porém, esse processo náo tem se voltado para ampliar, nos espaços acadêmicos, a temática das drogas, como primário para a aprendizagem do cuidado sobre uma problemática atual, e que se mostra a cada dia como de saúde pública.

Finalmente, é importante destacar a importância de investir na temática das drogas, de forma dialógica, reflexiva e crítica, quanto aos contextos que permeiam esta problemática junto à comunidade acadêmica, tendo as atividades de extensáo como um espaço propício a essa lógica.

\section{Referências}

ASSIS, R.; BONIFÁCIO, N. A formação docente na universidade: ensino, pesquisa e extensão. Educação e Fronteiras On-Line, Dourados/MS, v.1, n.3, p.36-50, set./dez. 2011. Disponível em: http://ojs.ws.ufgd.edu.br/index.php?journal=educacao\&page=article\&op=view\&path \%5B\%5D=1515\&path\%5B\%5D=pdf_97. Acesso em: 4 mar. 2016.

BARROS, H.M.; SANTOS, V.; MAZONI, C. et al. Neuroscience education for health profession undergraduates in a call-center for drug abuse prevention. Drug Alcohol Depend, v.98, n.3, p. 270-274, 2008.

BATISTA, N.; BATISTA, S.; GOLDENBERG, P. et al. O enfoque problematizador na formação de profissionais da saúde. Revista de Saúde Pública, v.39, n.2, p.231-237, 2005.

BRASIL. Lei № 10.216, de 06 de abril de 2002. Dispõe sobre a proteção e os direitos das pessoas portadoras de transtornos mentais e redireciona o modelo assistencial em saúde mental. Brasília, 2002. .Disponível em: http://www.planalto.gov.br/ccivil_03/leis/leis_2001/ I10216.htm. Acesso em: 12 fev. 2016.

BRASIL. Ministério da Educação. Lei № 11.096, de 13 de janeiro de 2005. Institui o Programa Universidade para todos (PROUNI). Brasília, 2005. Disponível em: http:// prouniportal.mec.gov.br/legislacao/legislacao-2005/87-lei-n-11-096-de-13-de-janeiro-de2005? path=legislacao-2005. Acesso em: 12 fev. 2016.

BRASIL. Ministério da Educação. Plano de Desenvolvimento da Educação: razões, princípios e programas. Brasília, 2007. Disponível em: http://portal.mec.gov.br. Acesso em: 12 fev. 2016.

BRASIL. Crack, é possível vencer. 2012. Disponível em: http://www.brasil.gov.br/ observatoriocrack/index.html. Acesso em: 20 ago. 2016. 
BRASIL. Legislação brasileira sobre educação. Série Legislação. 2.ed. Brasília: Edições Câmara, 2013. 358 p.

BRASÍLIA. Projeto Político Pedagógico Institucional da Universidade de Brasília. Brasília: UnB, 2011.

CHANDLER, R. K.; FLETCHER, B. W.; VOLKOW, N. D. Treating drug abuse and addiction in the criminal justice system: improving public health and safety. JAMA: The Journal of the American Medical Association, v.301, n.2, p.183-190, 2009.

DACKIS, C.; O'BRIEN, C. Cocaine dependence: a disease of the brain's reward centers. J Subst Abuse Treat., v.21, n.3, p. 111-117, Oct. 2001. Disponível em: http://www.ncbi.nlm. nih.gov/pubmed/11728784. Acesso em: 03 ago. 2016.

GALLASSI, A.; DOS SANTOS, V. O abuso de drogas: desafios e opções a prática profissional de saúde no Brasil. Brasília Médica, v.50, n.1, p. 51-57, 2013. 
LOBATO, P. L. M.; ABRANCHES, M.; RODRIGUES, T. V. A indissociabilidade ensino, pesquisa e extensão no Projeto Rondon Minas Resíduos Sólidos. 2012. Disponível em: <http://www1.pucminas.br/ documentos/forext_02.pdf>. Acesso em: 03 nov. 2016.

MILLER, N.; SHEPPARD, L. The role of the physician in addiction prevention and treatment. Psychiatr Clin North Am., v.22, n.2, p.489-505, 1999.

RIBEIRO, K.S. A experiência na extensão popular e a formação acadêmica em fisioterapia. Cad. CEDES, Campinas, v. 29, n. 79, p. 335-346, dez. 2009. Disponível em: <http://www.scielo.br/scielo.php?script=sci_ arttext\&pid=S01013262200900-0300004\&l-ng=en\&nrm=iso >. Acesso em: 06 mai. 2016.

RODRIGUES, G. M. Ensino, pesquisa e extensão universitária. 2011. Disponível em: $<$ http://www.estadao.com.br/noticias/impresso,ensino-pesquisa--e extensaouniversitaria $-, 793617,0$. htm >. Acesso em: 05 mai. 2016. 